\title{
Meta-Analysis of Yield Response of Hybrid Field Corn to Foliar Fungicides in the U.S. Corn Belt
}

\author{
P. A. Paul, L. V. Madden, C. A. Bradley, A. E. Robertson, G. P. Munkvold, G. Shaner, K. A. Wise, \\ D. K. Malvick, T. W. Allen, A. Grybauskas, P. Vincelli, and P. Esker
}

First and second authors: Department of Plant Pathology, The Ohio State University, Ohio Agricultural Research and Development Center, Wooster 44691; third author: Department of Crop Sciences, University of Illinois, Urbana 61801; fourth and fifth authors: Department of Plant Pathology, Iowa State University, Ames 50011; sixth and seventh authors: Department of Botany and Plant Pathology, Purdue University, West Lafayette, IN 47907; eighth author: Department of Plant Pathology, University of Minnesota, St. Paul 55108; ninth author: Mississippi State University, Delta Research and Extension Center, Stoneville 38776; tenth author: Department of Plant Science and Landscape Architecture, University of Maryland, College Park 20742; eleventh author: Department of Plant Pathology, University of Kentucky, Lexington 40546; and twelfth author: Department of Plant Pathology, University of Wisconsin, Madison 53706.

Accepted for publication 29 April 2011.

\section{ABSTRACT}

Paul, P. A., Madden, L. V., Bradley, C. A., Robertson, A. E., Munkvold, G. P., Shaner, G., Wise, K. A., Malvick, D. K., Allen, T. W., Grybauskas, A., Vincelli, P., and Esker, P. 2011. Meta-analysis of yield response of hybrid field corn to foliar fungicides in the U.S. Corn Belt. Phytopathology 101:1122-1132.

The use of foliar fungicides on field corn has increased greatly over the past 5 years in the United States in an attempt to increase yields, despite limited evidence that use of the fungicides is consistently profitable. To assess the value of using fungicides in grain corn production, randomeffects meta-analyses were performed on results from foliar fungicide experiments conducted during 2002 to 2009 in 14 states across the United States to determine the mean yield response to the fungicides azoxystrobin, pyraclostrobin, propiconazole + trifloxystrobin, and propiconazole + azoxystrobin. For all fungicides, the yield difference between treated and nontreated plots was highly variable among studies. All four fungicides resulted in a significant mean yield increase relative to the nontreated plots $(P<0.05)$. Mean yield difference was highest for propiconazole + trifloxystrobin $(390 \mathrm{~kg} / \mathrm{ha})$, followed by propiconazole + azoxystrobin $(331 \mathrm{~kg} / \mathrm{ha})$ and pyraclostrobin $(256 \mathrm{~kg} / \mathrm{ha})$, and lowest for azoxystrobin $(230 \mathrm{~kg} / \mathrm{ha}$ ). Baseline yield (mean yield in the nontreated plots) had a significant effect on yield for propiconazole + azoxystrobin $(P<0.05)$, whereas baseline foliar disease severity (mean severity in the nontreated plots) significantly affected the yield response to pyraclostrobin, propiconazole + trifloxystrobin, and propiconazole + azoxystrobin but not to azoxystrobin. Mean yield difference was generally higher in the lowest yield and higher disease severity categories than in the highest yield and lower disease categories. The probability of failing to recover the fungicide application cost $\left(p_{\text {loss }}\right)$ also was estimated for a range of grain corn prices and application costs. At the 10-year average corn grain price of $\$ 0.12 / \mathrm{kg}$ ( $\$ 2.97 / \mathrm{bushel})$ and application costs of $\$ 40$ to $95 / \mathrm{ha}, p_{\text {loss }}$ for disease severity $<5 \%$ was 0.55 to 0.98 for pyraclostrobin, 0.62 to 0.93 for propiconazole + trifloxystrobin, 0.58 to 0.89 for propiconazole + azoxystrobin, and 0.91 to 0.99 for azoxystrobin. When disease severity was $>5 \%$, the corresponding probabilities were 0.36 to $95,0.25$ to $0.69,0.25$ to 0.64 , and 0.37 to 0.98 for the four fungicides. In conclusion, the high $p_{\text {loss }}$ values found in most scenarios suggest that the use of these foliar fungicides is unlikely to be profitable when foliar disease severity is low and yield expectation is high.

Additional keywords: quinone outside inhibitor fungicides, research synthesis, risk analysis.
The use of foliar fungicides is often profitable in seed corn (Zea mays L.) production $(38,67,68)$ but has been much less profitable in grain corn production because of the substantially lower value of grain compared with seed. Profitable fungicide use in corn grown for grain is influenced by grain price and application costs and is strongly dependent on the yield potential and disease-susceptibility or resistance of the hybrid planted, and foliar disease intensity throughout the growing season (38). In the U.S. Corn Belt, several foliar diseases are of concern, depending on the production region, but gray leaf spot (GLS), caused by Cercospora zeae-maydis Tehon \& E. Y. Daniels, has been the disease of greatest concern since first becoming a problem in the 1980s and 1990s (31-33). The elevation of GLS from a disease of secondary importance to a major problem throughout the eastern United States and the Midwest paralleled the adoption of reduced tillage $(31,33)$. Disease severity tends to be higher in areas where susceptible hybrids are planted in no-till, continuous-corn fields $(10,33,49$,

Corresponding author: P. A. Paul; E-mail: paul.661@osu.edu

doi:10.1094/PHYTO-03-11-0091

(C) 2011 The American Phytopathological Society
66). However, the presence of corn residue on the soil surface, although increasing the risk of foliar disease caused by necrotrophic fungi, does not always lead to severe disease. Unless weather conditions are favorable for infection $(3,53,63)$ and sporulation (46), GLS may not reach yield-limiting levels (e.g., leaves above the ear become severely blighted) (1), even if residue is present. As a result, foliar fungicide applications for management of GLS (or other residue-borne diseases) may not be warranted, even when crop production practices favor GLS or other diseases.

Since 2006, there has been an increased interest in foliar fungicide application in corn (and other field crops) in the United States for reasons other than simply disease control (37). Claims of substantial yield increase in hybrid corn in response to foliar fungicides, even in the absence of foliar disease symptoms, have led to fungicide applications on several million hectares, with costs in the millions of dollars across the U.S. Corn Belt (37). Modern hybrids with high yield potential and new fungicide active ingredients with effects on crop physiology have been given as possible motivations for increased fungicide application in field corn production (37). In particular, based on bioassays and studies conducted under controlled conditions, quinone outside inhibitor (QoI) fungicides have been shown to induce 
physiological and developmental changes in plants, including retardation of senescence due to reduced oxidative stress (72), increased photosynthetic capacity, transient inhibition of respiration, inhibition of ethylene biosynthesis (15), and reduction of stomatal aperture and water loss through transpiration (14,39). These changes are believed to translate into greater stress tolerance and higher yields in QoI-treated crops under field conditions, and have prompted recent additions to the label of one of the most widely used QoI fungicide products, $23.6 \%$ pyraclostrobin (Headline; BASF Corporation Agricultural Products, Research Triangle Park, NC). In 2009, the U.S. Environmental Protection Agency granted a supplemental label for the use of Headline for disease control and its "plant health" benefit, which may lead to more widespread use of fungicides without regard to disease risk.

Claims of substantial yield increases in response to QoI-based fungicides have not always been substantiated by adequate data analysis and research synthesis. For instance, conclusions regarding the overall yield benefit and economics of fungicide use in corn have been based largely on tests of treatment significance from individual trials, a tally of the number of trials with significant results (vote counting), and simple unweighted arithmetic mean yield difference between treatments across multiple trials $(27,37)$. There are several reasons why these approaches may not necessarily be appropriate for the synthesis of this type of data $(4,18)$. Simple means of effect sizes across studies give the same weight to studies with high variability (low precision) and to those with low variability (high precision) and, hence, do not account for inherent differences among trials (including betweenstudy variability and the presence of study-specific conditions as well as unequal within-study variability) that likely influence the magnitude and precision of the estimated overall fungicide effect. Madden and Paul (36) presented a discussion of the fallacy of research synthesis based on vote counting and provided several justifications why a quantitative method known as meta-analysis is much more appropriate. In brief, the statistical power of the vote-counting method is generally very low, perhaps lower than that of the majority of the individual studies, and may actually decrease as the number of studies increase. The statistical power of meta-analysis, on the other hand, is higher than that of individual analyses and vote counting and, therefore, this approach is less likely to lead to erroneous conclusions regarding treatment effects $(4,21,36)$.

Meta-analysis, a quantitative synthesis of research findings from multiple individual trials $(4,18,34,44)$, provides an alternative to narrative review or qualitative research synthesis. In metaanalysis, an overall effect size is estimated, in which each individual effect size is given a weight that is an inverse function of (i) the within-study variance and, for a random-effects analysis, (ii) the between-study variance. An effect size is any statistic (mean yield difference in this case) that can be used to evaluate the overall effect of some treatment or the strength of a relationship between variables $(4,17,34,36)$. Both within- and betweenstudy variability are considered when estimating the overall mean effect size through an iterative weighing algorithm. The objective of this study was to use meta-analysis to determine (i) the overall mean effect of QoI-based fungicide treatments on grain yield of hybrid field corn and the corresponding confidence interval (CI) and between-study variability, (ii) the influence of categorical levels of yield and foliar disease severity in the nontreated plot (baseline) on mean effect size, and (iii) the probability that there is an economic benefit to applying a fungicide in a randomly selected study or field under a range of scenarios of grain market prices and application costs.

\section{MATERIALS AND METHODS}

Data set. The data used in this investigation were obtained from fungicide research and on-farm studies conducted by uni- versity researchers (the co-authors of this article) and from summaries of foliar fungicide studies published in Fungicide and Nematicide Tests (F\&N Tests) and Plant Disease Management Reports (PDMR) (The American Phytopathological Society, St. Paul, MN). For the purpose of this research, a study is defined as an entry (a row in the data matrix) with a unique combination of year, location, hybrid, and corresponding yield and disease (when available) data. In order for a study to be considered for inclusion in the analysis, it had to be replicated, with a random assignment of treatments consisting of a single application of at least one of the following fungicides: $23.6 \%$ pyraclostrobin (Headline; BASF Corporation Agricultural Products), $11.4 \%$ propiconazole $+11.4 \%$ trifloxystrobin (Stratego; Bayer CropScience, Research Triangle Park, NC), 7\% azoxystrobin $+11.7 \%$ propiconazole (Quilt; Syngenta Crop Protection Inc., Greensboro, NC), or $22.9 \%$ azoxystrobin (Quadris; Syngenta Crop Protection Inc.) applied at labelrecommended rates $(438 \mathrm{ml} / \mathrm{ha}$ for Headline, $730 \mathrm{ml} / \mathrm{ha}$ for Stratego, 1,023 $\mathrm{ml} / \mathrm{ha}$ for Quilt, and $658 \mathrm{ml} / \mathrm{ha}$ for Quadris) between the VT (tassel emergence) and R1 (silk emergence) growth stages (52). Studies also had to have some measure of yield (volume or weight per unit area) for the nontreated comparison plots and at least one of the fungicide treatments and some measure of variability of the yield response, such as the least significant difference or coefficient of variation. Inclusion of information on disease severity was not a criterion for selection because this research synthesis encompasses situations with or without visible foliar disease. To be included, studies had to be published by February 2011 and report on results from 2009 or earlier.

Unpublished summaries and raw data were gathered from a total of 187 studies conducted by the co-authors of this article. Most of the studies were conducted with fungicide treatments and a nontreated check in a randomized complete block design; however, some studies (25\%) had fungicide treatment and hybrid in a split-plot arrangement, with hybrid as the whole-plot factor. For the latter group of studies, each hybrid was treated as a separate observation in the meta-analysis, because hybrids were in separate replicated plots with fungicide treatments randomized within each hybrid. The number of replicate blocks ranged from two to six, and experimental units were 7.62 to several hundred meters long $\times 3.05$ to several meters wide. The specific fungicide treatments varied among studies but, in all of the 187 selected trials, one or more of the treatments satisfied the aforementioned criteria. In most cases, a nonionic surfactant was added with the fungicide mixture at a rate of 0.25 to $1.0 \%$ (vol/vol). Treatments were either air applied (in 13 studies) or ground applied using tractor-mounted sprayers, specialized high-clearance sprayers, or hand-held booms, at 46.67 to 187.08 liters/ha. Grain was harvested using a research-plot or commercial combine harvester and yield was adjusted to $15.5 \%$ moisture. Yield was converted from the original unit of bushels per acre to metric tons per hectare, based on a test weight of $25 \mathrm{~kg} / \mathrm{bushel}$.

Using corn and azoxystrobin, pyraclostrobin, or trifloxystrobin as keywords, the PDMR search engine was used to screen for trials that met the aforementioned criteria. In general, for any given issue of PDMR, each published summary consisted of a table with mean grain yield for fungicide-treated and nontreated plots from a single trial. However, in some cases, the published summary consisted of data from separate trials (with the same or similar sets of treatments) conducted at multiple locations or using different hybrids at the same location. Each trial was considered an individual study for the analysis. Data were collected from a total of 25 PDMR studies for the period 2002 to 2009 (68,22-25,28-30,58-62,69-71). Eight additional studies were found in PDMR, however, in which four of these were not considered because they did not meet the aforementioned study selection criteria. The other four PDMR studies $(41,47,48,56)$ were already included in the dataset as raw data collected from the co-authors. 
In total, 212 studies (187 as raw data from experiments and 25 as summaries from PDMR) were compiled from 14 states for the period 2002 to 2009: 86 from Ohio, 33 from Iowa, 23 from Illinois, 24 from Minnesota, 8 from Maryland, and 38 from Virginia, Mississippi, Kansas, Wisconsin, Missouri, Kentucky, Indiana, North Dakota, and Nebraska. Among the fungicide treatments evaluated in this study, pyraclostrobin was tested in 172 studies (67 from Ohio, 31 from Iowa, 17 from Illinois, 19 from Minnesota, and 38 from the other 10 states), propiconazole + trifloxystrobin in 72 studies (24 from Ohio, 10 from Iowa, 23 from Illinois, and 15 from 8 other states), propiconazole + azoxystrobin in 61 studies (17 from Illinois and 44 from 12 other states), and azoxystrobin in 25 studies (16 from Illinois, 4 from Iowa, 3 from Indiana, and 2 from Ohio).

Meta-analysis of fungicide effect on grain yield. For each study, the difference in mean yield between treated and nontreated plots for each fungicide tested was used as the effect size to determine the overall mean yield response (mean effect size) of hybrid corn to QoI-based fungicide treatments. For instance, if $\bar{X}_{\text {Check }}$ is the mean yield for the nontreated plot in a study and $\bar{X}_{\text {Treated }}$ the mean yield for a treatment in a study (where "Treated" corresponds to either pyraclostrobin, propiconazole + trifloxystrobin, propiconazole + azoxystrobin, or azoxystrobin), then the effect size ( $D$, unstandardized mean difference) was computed simply as $D=\bar{X}_{\text {Treated }}-\bar{X}_{\text {Check }}(4,34,36)$. $D$ is an intuitive and informative summary of fungicide effect on grain yield and, as such, an appropriate effect size for the questions being asked in this investigation (36).

Separate random-effects meta-analyses were performed as described by Paul et al. (42) and Madden and Paul (36) for each fungicide to estimate the overall mean effect size $(\bar{D})$ and to determine the variability in effect size among studies. Models were fitted to the data in PROC MIXED of SAS using maximum likelihood as described elsewhere $(36,40,55,64)$. In the analysis, each study was given an initial weight that was inversely proportional to the sampling variance (within-study variance) of the mean difference, computed as $s_{i}^{2}=(2 \times V) / r$, where the $i$ subscript refers to the $i$ th study and $r$ the number of replicates within a study. $V$ is the mean square error (residual variance) from an analysis of variance (ANOVA) of the effect of fungicide treatment on yield. For studies for which the original data were available (fungicide research and on-farm strip trials), the residual variance was obtained directly from a preliminary ANOVA of the raw data in PROC MIXED (35) of SAS (SAS Institute Inc., Cary, NC). For studies from F\&N Tests and PDMR for which only the means and the least significant difference (LSD) were available, $V$ was calculated from the presented LSD as described previously $(36,42)$. In the maximum likelihood approach, the initial weights are updated in an iterative fashion by inclusion of the between-study variance.

The random effects model can be written as $D_{i} \sim N\left(\mu, s_{i}^{2}+\sigma^{2}\right)$, where $D_{i}$ is the mean difference (effect size) in yield between the treatment and the nontreated for the $i$ th study $(i=1, \ldots, k), \sim N(\bullet)$ indicates a normal distribution, $\mu$ is the expected value of $D$ (mean effect size), $\sigma^{2}$ is the between-study variance, and $s_{i}^{2}$ is the within-study variance for the $i$ th study. Study was considered a random effect in each analysis, and models were fitted using $D_{i}$ as the response variable in the model statement. The within-study variances were incorporated (as fixed weights, $1 / s_{i}^{2}$ ) into the model fitting procedure using the weight statement in PROC MIXED. The estimate of $\mu$ equals $\bar{D}$, and separate values $\left(\bar{D}^{P Y R A}, \bar{D}^{P R O P+T R I F}, \bar{D}^{P R O P+A Z O X}\right.$, and $\left.\bar{D}^{A Z O X}\right)$ were computed for each fungicide in separate analyses. Standard normal test statistics $(Z)(11,19)$ were used to determine whether $\bar{D}^{\text {PYRA }}, \bar{D}^{P R O P+T R I F}, \bar{D}^{\text {PROP }+A Z O X}$, and $\bar{D}^{\text {AZOX }}$ were significantly different from zero. Standard errors of the effect sizes were determined by PROC MIXED based on mixed model theory (35) and used to determine the $95 \%$ CIs for mean effect sizes, as described elsewhere $(4,34)$.
Yield response to fungicides as influenced by baseline yield and foliar disease severity. Two of the most common explanations for differences in yield response to fungicide treatments among trials are the difference in baseline yield (YLD_BASE) among hybrids used in the trials and difference in disease intensity. YLD_BASE differences could be a function of several factors acting separately or in combination to affect yield, including the yield potential of the hybrid, soil and weather conditions, and stresses caused by pests and diseases. For the population of studies included in this investigation, mean yield and foliar disease severity (when reported) in the nontreated check were used as measures of YLD_BASE and baseline disease severity (DIS_BASE), respectively, in the study. YLD_BASE served a surrogate for possible biotic and abiotic factors affecting yield in a given study. This is similar to the approach taken in medical statistics, where the response variable in the control is used to represent baseline risk of disease, disorder, or clinical condition $(2,9)$.

Based on the range (difference between minimum and maximum yields) and distribution of the yield data for the nontreated plots, studies were grouped into different categories, using histograms as a guide for defining cutoffs (natural breaks in the distribution). For pyraclostrobin and propiconazole + trifloxystrobin, the categories were (i) YLD_BASE1 $\leq 9.1$ metric tons per hectare (MT/ha) $(\approx 145$ bushels/acre), (ii) YLD_BASE2 of 9.1 to 11.9 MT/ha ( $\approx 145$ and 190 bushels/acre), and (iii) YLD_BASE2 $\geq$ 11.9 MT/ha. There were 57, 61, and 54 studies with pyraclostrobin in categories i, ii, and iii, respectively, and 18, 17, and 37 studies with propiconazole + trifloxystrobin in the three categories. For propiconazole + azoxystrobin and azoxystrobin, the categories were (i) YLD_BASE1 < $11.9 \mathrm{MT} / \mathrm{ha}$ and (ii) YLD_BASE2 $\geq 11.9 \mathrm{MT} / \mathrm{ha}$. There were 28 and 33 studies with propiconazole + azoxystrobin in the first and second categories, respectively, and 12 and 13 with azoxystrobin in the two categories.

For each fungicide, if foliar disease severity (percent diseased leaf area) was reported, studies were grouped into two categories based on ear leaf severity in the nontreated plot between the R4 and R6 growth stages (52): (i) DIS_BASE1 < 5\% and (ii) DIS BASE2 $\geq 5 \%$. The $5 \%$ cutoff was based on a preliminary summary of a subset of the data (data collected in 2008) which showed a clear difference in yield response between the two categories (G. Shaner, unpublished). The diseases reported were GLS (C. zeae-maydis), northern corn leaf blight (Exserohilum turcicum), and common rust (Puccinia sorghi). GLS was the disease most frequently reported, either as the only disease or in combination with one or both of the other two diseases as total diseased ear leaf area. A third category, DIS_BASE3, was created for studies without reported foliar disease severity. These studies may represent situations when visible disease symptoms were not observed (and not mentioned) or when disease severity assessments were not conducted or reported. Thus, it would likely represent a diverse set of conditions. Studies in which disease intensity was reposted as area under the disease progress curve or severity on an ordinal rating scale were included in the third category, unless the severity category could have been deduced from the reports. For instance, in one study (61), GLS severity was reported on a 1-to-5 scale, with $1=$ a trace number of lesions on leaves below the ear, none on leaves above; 2 = many lesions on leaves below the ear, trace above; $3=$ severe lesion development on leaves below the ear, all leaves above with lesions; $4=$ all leaves with severe lesion development, but green tissue still visible; and $5=$ all leaves dry and dead. The ordinal scores were accompanied by corresponding whole-plant severity scores ( 0 to $100 \%$ ), with a 3 on the ordinal scale corresponding to $35 \%$ whole-plant severity, 4 on the ordinal scale to $\approx 75 \%$ whole-plant severity, and 5 to $>96 \%$ whole-plant severity. These severity scores, on both scales, corresponded to $>5 \%$ GLS severity on the 
ear leaf (E. Stromberg, personal communication). Foliar disease severity data were available for 101 studies with pyraclostrobin (65 in the first category and 36 in the second), 59 with propiconazole + trifloxystrobin ( 28 in the first category and 31 in the second), 37 with propiconazole + azoxystrobin (15 and 22 in categories i and ii, respectively), and 20 with azoxystrobin (7 and 14 in categories i and ii, respectively).

For this part of the study, the meta-analytical models were expanded to evaluate the effect of YLD_BASE and DIS_BASE, categorical moderator variables $(4,34)$, on the effect size $(D)$. This is a common analytical approach in meta-analysis when heterogeneity of the effect sizes between studies is verified $(42,43)$. Because the moderator variables were treated as fixed effects in the analysis, the overall model was a mixed effect model. Separate models were fitted for each fungicide and each moderator variable in PROC MIXED to determine whether YLD_BASE and DIS_BASE significantly affected $D$ and to estimate separate $\bar{D}$ values for each level of each moderator variable. Models were fitted using the same within-study (sampling) variances as above in the analysis without the moderator variable. With the moderator variable, the mixed-effect model can be written as $D_{i} \sim N\left(\mu, s_{i}^{2}+\sigma^{2}\right)$, where $\delta_{i}$ is the effect of the moderator variable for the $i$ th study on the mean effect size. All other terms are as described previously. In this model, the mean effect size is not a constant across all studies but a sum of an overall mean $(\mu)$ and the effect of the moderator variable $\left(\delta_{i}\right)$. To determine whether the moderator variable had a significant effect on the mean effect sizes, $\chi^{2}$ tests $(11,19,34,42)$ were used, and linear contrasts were used to estimate the mean effect sizes and their standard errors and CIs for each level of the moderator variable.

Study heterogeneity. A likelihood ratio statistic (LRS) was used to test whether the between-study variance was $>0$ (36). For each fungicide, the meta-analytical model was refitted without the random effect of study (a fixed-effect model) and the difference in -2 times the log-likelihood between the fixed- and random-effects model fits (the LRS) was determined. Under the null hypothesis of $\sigma^{2}=0$, LRS has a distribution that is a mixture of $\chi^{2}$ distributions with 0 and 1 degrees of freedom $(35,36)$. In addition, the $R^{2}$ statistic (this is not the coefficient of determination) of Higgins and Thompson (20) was calculated. This is a statistic used to determine the impact of the between-study variability on the effect sizes. $R^{2}>1.5$ indicates considerable heterogeneity and the need to account for between-study variability in the analysis.

Prediction and risk analysis. Although the overall mean yield difference $(\bar{D})$ can be used to determine average cost and benefits of fungicide application in the long run, $\bar{D}$ alone cannot reveal the chance of a given yield response in any single field or study. It is important for corn producers and researchers to know what can be expected of a certain treatment or crop management practice in a future trial or growing season. It would also be of interest to estimate the risk of losing money (because of increased production cost) if a certain production practice is used when it is not warranted. One can estimate the probability of a certain effect-size outcome based on results from previous studies in a meta-analysis (36). For instance, for each of the fungicides evaluated in this investigation, the mean effect size $(\bar{D})$ and estimated between-study variance ( $\hat{\sigma}^{2}$ ) from the meta-analyses can be used to estimate the probability of the yield response to fungicide in a new randomly selected study-done in the same manner as the studies considered in this analysis-being lower (or higher) than some constant $(C)$. This probability is estimated as $p=\phi[(C-$ $\bar{D}) / \hat{\sigma}]$, where $\phi(\bullet)$ is the cumulative standard-normal function and $\hat{\sigma}$ is the estimated between-study standard deviation $(36,43$, 64). In particular, one can estimate the probability that the yield response (effect size in a future study) is lower than that necessary to offset the cost of the fungicide treatment (product plus application costs). This probability is the risk of failing to recover the cost of applying the fungicide.
Assuming grain prices of $\$ 79$ to 276 U.S./MT $(\approx \$ 2$ to 7 U.S./ bushel) and fungicide application costs of $\$ 40$ to 95 U.S./ha ( $\approx \$ 16$ to 40 U.S./acre), the minimum yield increase in response to fungicide treatment necessary to break even was estimated for each combination of grain price and application cost. $\bar{D}$ and $\hat{\sigma}^{2}$ from the meta-analyses, with disease severity as moderator variable, were then used to estimate the probability of not achieving the minimum breakeven yield increase in a new study, for each selected grain price-application cost combination, fungicide, and baseline disease class. For the purpose of this investigation, this probability was called $p_{\text {loss }}$. For instance, assuming all other crop production costs remain constant, if fungicide application cost is $\$ 62$ U.S./ha and grain market price is $\$ 197$ U.S./MT, it would take a yield increase of $C=314 \mathrm{~kg} / \mathrm{ha}$ to offset the cost of fungicide application. Hence, the probability of $D<314 \mathrm{~kg} / \mathrm{ha}$ can be estimated as $p_{\text {loss }}=\phi[(314-\bar{D}) / \hat{\sigma}]$.

\section{RESULTS}

Yield response and meta-analysis. Mean grain yield varied among studies and among fungicide treatments. In general, mean yield was higher in plots treated with fungicides than in the nontreated plots (Fig. 1). For all fungicides, the difference in mean yield between treated and nontreated plots $\left(D=\bar{X}_{\text {Treated }}-\bar{X}_{\text {Check }}\right)$ varied among studies. A subset of the studies had a negative yield response, meaning that the nontreated plots had higher mean yields than the fungicide-treated plots (Fig. 2). This occurred in 26 to $48 \%$ of the studies, depending on the fungicide. $D$ was $-1,940$ to $2,211 \mathrm{~kg} / \mathrm{ha}$ for pyraclostrobin, $-1,793$ to $2,999 \mathrm{~kg} / \mathrm{ha}$ for propiconazole + trifloxystrobin, $-2,368$ to $3,034 \mathrm{~kg} / \mathrm{ha}$ for propiconazole + azoxystrobin, and -886 to $1,821 \mathrm{~kg} / \mathrm{ha}$ for azoxystrobin. As indicated by the vertical standard error bars in Figure 2, a measure of the within-study variability of the effect size, the precision with which $D$ was estimated, varied substantially among studies for all of the tested fungicides.

Based on the standard normal test statistics from the metaanalyses, the overall mean yield difference (the effect size, $\bar{D}$ ) was positive and significantly different from zero for all of the tested fungicides (Table 1). $\bar{D}$ was highest for propiconazole + trifloxystrobin followed by propiconazole + azoxystrobin and pyraclostrobin, and lowest for azoxystrobin. The width of the 95\% CI around $\bar{D}$ was narrowest for pyraclostrobin and increased with decreasing sample size (number of studies), being

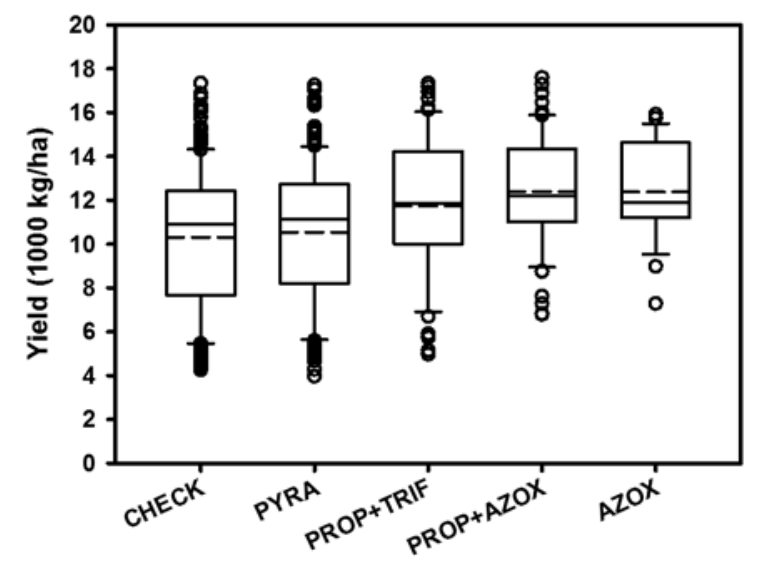

Fig. 1. Box plots summarizing the distribution of grain yield of hybrid corn treated with the fungicides pyraclostrobin (PYRA) propiconazole + trifloxystrobin (PROP+TRIF), propiconazole + azoxystrobin (PROP+AZOX), and azoxystrobin (AZOX) and the nontreated plot. Solid and dashed lines within each box represent median and mean, respectively. Top and bottom lines of the boxes represent the 75 th and 25 th percentiles of the data, respectively. Vertical bars extending beyond the boxes represent the 10th and 90th percentiles, whereas circles indicate outliers. 
the widest for azoxystrobin. Hence, the precision with which the effect size was estimated was partly affected by the number of studies in the analysis. For instance, there were 147 more studies with pyraclostrobin than with azoxystrobin, with the width of the $95 \%$ CI being $280 \mathrm{~kg} / \mathrm{ha}$ (4.46 bushels/acre) narrower for the former than the latter fungicide.

Effect of moderator variables and between-study variability. Based on the $\chi^{2}$ test statistics from the analyses, the effect of YLD_BASE on the effect size was statistically significant for propiconazole + azoxystrobin $(P=0.03)$, marginally significant for propiconazole + trifloxystrobin $(P=0.07)$, but not significant for azoxystrobin $(P=0.103)$ and pyraclostrobin $(P=0.805)$. Studies in the lowest YLD_BASE category consistently had higher mean yield responses to the fungicides than those in the highest yield category (Fig. 3). For propiconazole + trifloxy- strobin, $\bar{D}^{\text {PROP+TRIF }}$ was significantly $(P=0.02)$ higher for YLD_BASE1 (YLD_BASE $\leq 9.1 \mathrm{MT} / \mathrm{ha}$ ) than YLD_BASE3 (YLD_BASE $\geq 11.9$ MT/ha). However, the differences between YLD_BASE1 versus YLD_BASE2 and YLD_BASE2 versus YLD_BASE3 were not statistically significant. Similarly, for propiconazole + azoxystrobin, YLD_BASE1 (YLD_BASE $<11.9$ MT/ha) had a significantly $(P=0.03)$ higher $\bar{D}^{P R O P+A Z O X}$ (Table 2) than YLD_BASE2 (YLD_BASE $\geq 11.9 \mathrm{MT} / \mathrm{ha}$ ). The width of the $95 \%$ CI around $\bar{D}$ (Fig. 3 ) varied from one YLD_BASE category to another, tending to be narrower for categories with the larger sample sizes (Fig. 3).

The effect of DIS_BASE on the mean effect size was statistically significant for pyraclostrobin $(P=0.008)$, propiconazole + trifloxystrobin $(P=0.030)$, and propiconazole + azoxystrobin $(P=0.012)$ but not significant for azoxystrobin $(P=0.239)$. For

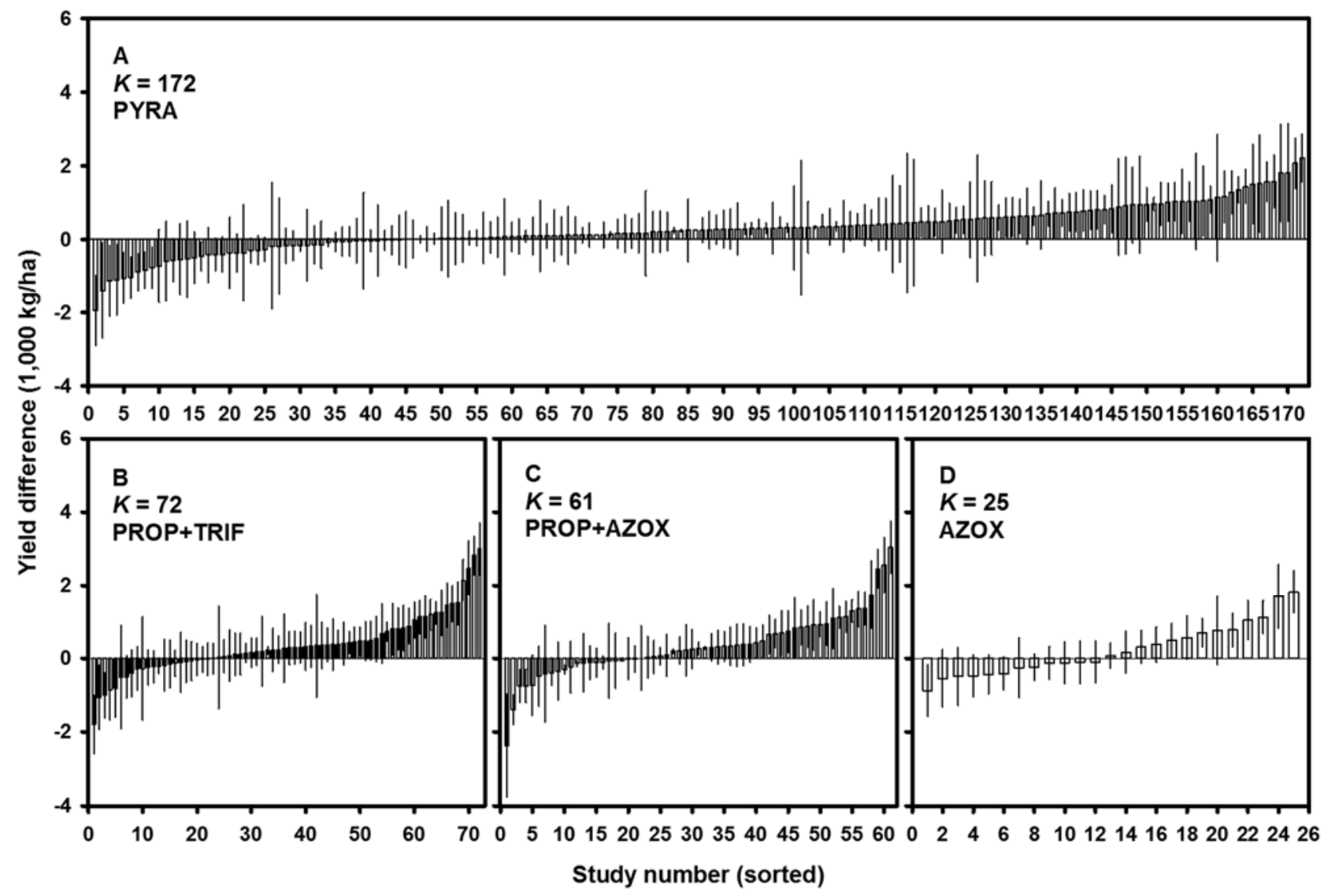

Fig. 2. Mean yield difference between fungicide treatments and the nontreated, sorted from the lowest to the highest, for the fungicides A, pyraclostrobin, (PYRA); B, propiconazole + trifloxystrobin (PROP+TRIF); C, propiconazole + azoxystrobin (PROP+AZOX); and D, azoxystrobin (AZOX). Each bar represents the yield difference averaged across two to six replicates and the vertical lines extending from each bar are standard errors. $K$ is the number of studies in which the mean yield difference was determined for each fungicide. Studies came from a total of 18 articles published in Plant Disease Management Reports (with some articles reporting on multiple studies) and 187 trials conducted by the co-authors of this article.

TABLE 1. Effect sizes and corresponding statistics for the effect of fungicides on yield of hybrid field corn

\begin{tabular}{|c|c|c|c|c|c|c|c|}
\hline \multirow[b]{2}{*}{ Fungicide $^{\mathrm{a}}$} & \multirow[b]{2}{*}{$k^{\mathrm{b}}$} & \multicolumn{6}{|c|}{ Statistics $^{\mathrm{c}}$} \\
\hline & & $\bar{D}$ & $\operatorname{se}(\bar{D})$ & $C I_{L}$ & $C I_{U}$ & $Z$ & $P$ \\
\hline PYRA & 172 & $255.91(4.08)$ & 36.91 & 183.05 & 328.76 & 6.93 & $<0.001$ \\
\hline PROP+TRIF & 72 & $390.39(6.22)$ & 83.02 & 224.86 & 555.91 & 4.70 & $<0.001$ \\
\hline $\mathrm{PROP}+\mathrm{AZOX}$ & 61 & $331.19(5.27)$ & 91.39 & 148.38 & 514.01 & 3.62 & 0.001 \\
\hline AZOX & 25 & $229.75(3.67)$ & 103.11 & 16.95 & 442.56 & 1.64 & 0.036 \\
\hline
\end{tabular}

a Active ingredients: PYRA = pyraclostrobin, $\mathrm{PROP}=$ propiconazole, $\mathrm{TRIF}=$ trifloxystrobin, and AZOX = azoxystrobin.

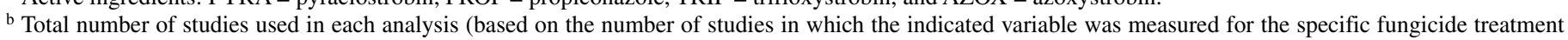
and the control). The dataset consisted of 25 studies from articles published in Plant Disease Management Reports (with some articles dealing with multiple studies) and 187 from experiments conducted by the co-authors of this article.

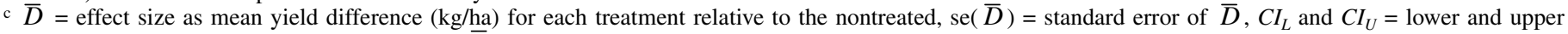

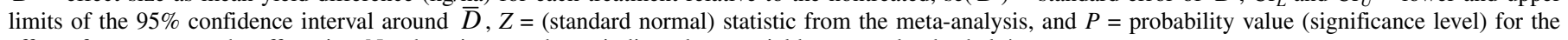
effect of treatment on the effect size. Numbers in parentheses indicated mean yield converted to bushels/acre. 
the first three fungicides, $\bar{D}$ was significantly higher in DIS_BASE2 (foliar disease severity $\geq 5 \%$ ) than in one or both of the other two categories, DIS_BASE1 (severity < 5\%) and DIS_BASE3 (trials without reported foliar disease severity). However, $\bar{D}$ was not significantly different between DIS_BASE1 and DIS_BASE3, and the difference between DIS_BASE2 and DIS_BASE1 was not statistically significant for each fungicide (Table 2). Depending on the fungicide, studies in the high DIS_BASE2 category had a 114 to $400 \mathrm{~kg} / \mathrm{ha}$ higher mean yield than those in the DIS_BASE1 category (Table 2; Fig. 3). For both DIS_BASE categories, the width of the $95 \%$ CI around the effect size was wider for azoxystrobin than for the other fungicides (Fig. $3 \mathrm{H})$. With $<15$ studies for some moderator-variable categories for azoxystrobin, estimated effect sizes for each category would be imprecise for this fungicide $(4,34)$. The results are still shown in the figure, however, for comparisons with the other treatments.

The effect of DIS_BASE3 (no reported foliar disease) on the effect sizes was ambiguous, as anticipated. This category likely
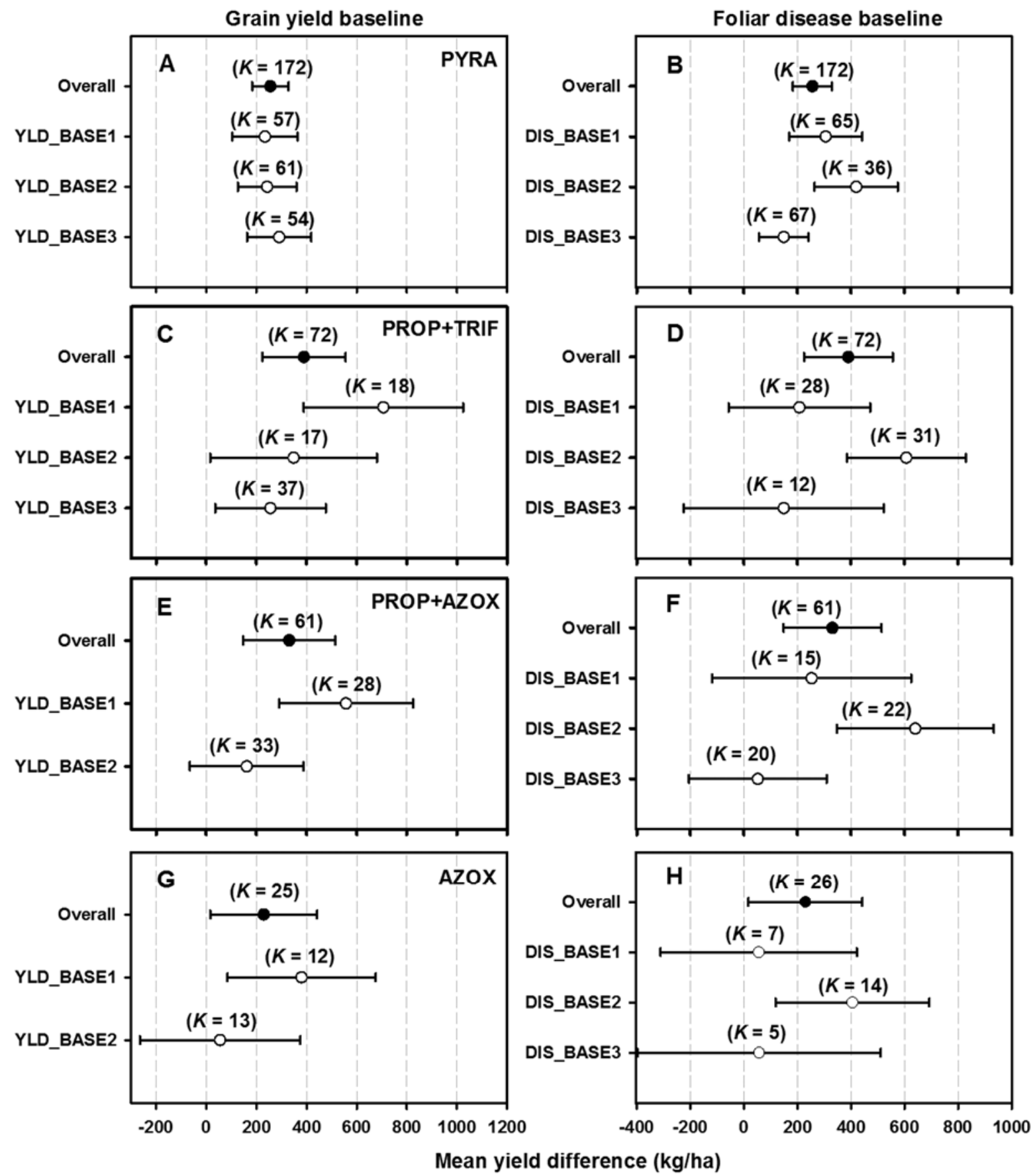

Fig. 3. Mean yield differences between fungicide-treated and nontreated plots and their $95 \%$ confidence intervals (horizontal bar) for all studies (Overall) and for studies categorized according to baseline yield (YLD_BASE, mean grain yield in the nontreated plot; left column) and baseline foliar disease severity (DIS_BASE, mean disease severity on the ear leaf in the nontreated, between the dough and dent growth stages) for the fungicides A and B, pyraclostrobin, (PYRA); C and D, propiconazole + trifloxystrobin (PROP+TRIF); $\mathbf{E}$ and F, propiconazole + azoxystrobin (PROP+AZOX); and $\mathbf{G}$ and $\mathbf{H}$, azoxystrobin (AZOX). For PYRA and PROP+TRIF, YLD_BASE1 = YLD_BASE $\leq$ 9.1 MT/ha, YLD_BASE2 = YLD_BASE of 9.1-11.9 MT/ha, and YLD_BASE3 = YLD_BASE $\geq 11.9$ MT/ha. For PROP+AZOX and AZOX, YLD_BASE1 = YLD_BASE $<11.9$ MT/ha and YLD_BASE2 = YLD_BASE $\geq 11.9$ MT/ha. DIS_BASE1 = DIS_BASE $<$ $5 \%$, DIS_BASE2 $=$ DIS_BASE $\geq 5 \%$ severity, and DIS_BASE3 = studies without reported disease severity. Confidence intervals show precision of the means but do not directly indicate significant differences. See Table 2 for contrasts of means. $K$ is the total number of studies (Overall) and the number of studies in each category. The dataset consisted of 25 studies from articles published in Plant Disease Management Reports (with some articles dealing with multiple studies) and 187 from experiments conducted by the co-authors of this article. 
includes a diverse collection of unreported disease levels, for different diseases, including those with no actual foliar disease being present (or found). The mean effect size for this category was typically the lowest numerically of the three DIS_BASE categories but the CIs were also quite wide for some treatments.

Based on likelihood ratio test, the estimated between-study variance $\left(\hat{\sigma}^{2}\right)$ was significantly different from zero $(P<0.05)$ for models fitted with and without moderator variables for three of the four tested fungicides (Table 3). This test indicated that the random-effects meta-analysis model was appropriate, fitting the data significantly better than a fixed-effects model (model with zero between-study variances or covariances $)(P<0.05)$ for pyraclostrobin, propiconazole + trifloxystrobin, and propiconazole + azoxystrobin but not azoxystrobin. The $R^{2}$ statistics (20) were $>1.5$ for the first three mean effect sizes in Table 3, indicating that there was considerable heterogeneity among the studies with pyraclostrobin, propiconazole + trifloxystrobin, and propiconazole + azoxystrobin and, as such, the between-study variability needed to be accounted for in the analyses.
In all cases, accounting for the effects of YLD_BASE and DIS_BASE on the effect size led to a reduction in $\hat{\sigma}^{2}$. In general, DIS_BASE explained a greater proportion of the between study variability than did YLD_BASE (Table 3).

Prediction and risk analysis. Based on estimated break-even grain yield for a range of fungicide application cost-grain price combinations, and the statistics ( $\bar{D}$ and $\left.\hat{\sigma}^{2}\right)$ from the metaanalyses reported here, the probability of the expected yield response in a new randomly selected trial being insufficient to offset the cost of fungicide application $\left(p_{\text {loss }}\right)$ was estimated. For almost all of the grain price-application cost combinations evaluated $(85 \%), p_{\text {loss }}$ was $>0.5$ when foliar disease severity in the nontreated plot (DIS_BASE) was $<5 \%$ (Fig. 4A, C, E, and G). On the other hand, $p_{\text {loss }}$ was $>0.5$ for only $33 \%$ of the grain priceapplication cost combinations, when disease severity was $\geq 5 \%$ (Fig. 4B, D, F, and H). As required based on the probability formula, for all four fungicides and both DIS_BASE categories, the $p_{\text {loss }}$ values increased with increasing fungicide application cost and, at any given application cost, decreased with increasing

TABLE 2. Differences between mean effect sizes $\left(\bar{D}_{D i f f}\right)$ and corresponding $\chi^{2}$ statistics and probability values $(P)$ for comparisons between categories of moderator variables for evaluating the effects of foliar fungicides on grain yield of hybrid corn, based on random-effects meta-analyses

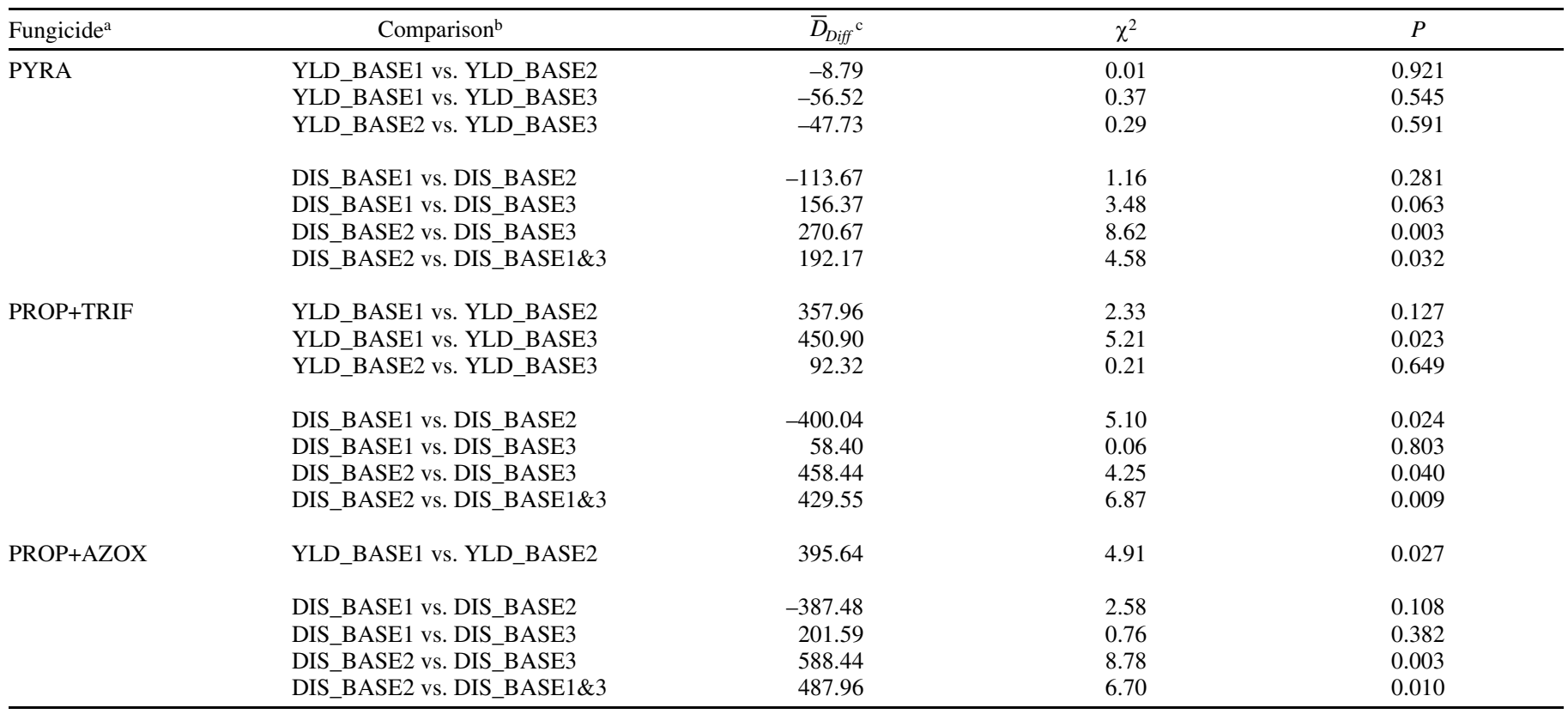

a Active ingredients: PYRA = pyraclostrobin, $\mathrm{PROP}=$ propiconazole, TRIF = trifloxystrobin, and AZOX = azoxystrobin.

b Comparisons between categories of baseline yield (YLD_BASE, mean grain yield in the nontreated plot) and baseline foliar disease severity (DIS_BASE, mean disease severity on the ear leaf in the nontreated, between the R4 and R6 growth stages). For PYRA and PROP+TRIF, YLD_BASE1 = YLD_BASE $\leq$ 9.1 MT/ha, YLD_BASE2 = YLD_BASE of 9.1 to $11.9 \mathrm{MT} / \mathrm{ha}$, and YLD_BASE3 = YLD_BASE $\geq 11.9 \mathrm{MT} / \mathrm{h}$. For PROP+AZOX, YLD_BASE1 = YLD_BASE < 11.9 MT/ha and YLD_BASE2 $=$ YLD_BASE $\geq 11.9$ MT/ha. DIS_BASE1 $=$ DIS_BASE $<$ 5\%, DIS_BASE2 $=$ DIS_BASE $\geq 5 \%$ severity, and DIS_BASE3 = studies without reported disease severity.

c $\bar{D}=$ effect size as mean yield difference $(\mathrm{kg} / \mathrm{ha})$ for each treatment relative to the nontreated plot.

TABLE 3. Estimated between-study variance and corresponding statistics from random-effects meta-analysis of the effect of fungicides on yield of hybrid field corn

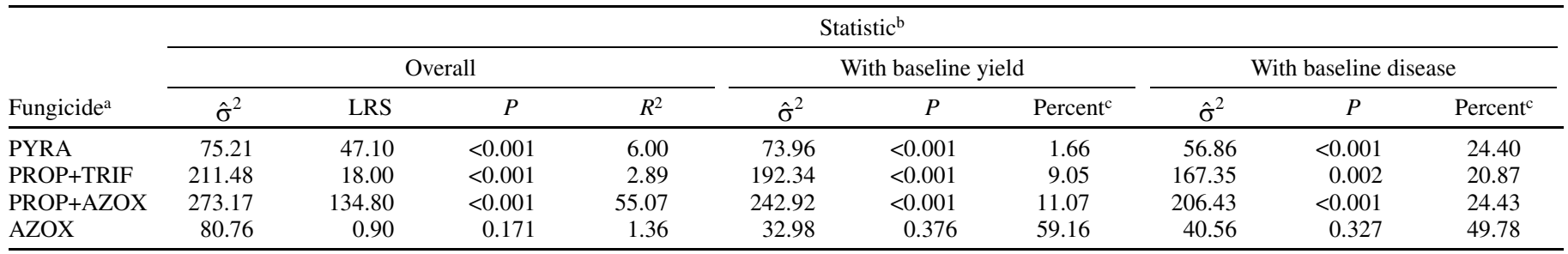

a Active ingredients: PYRA = pyraclostrobin, $\mathrm{PROP}=$ propiconazole, $\mathrm{TRIF}=$ trifloxystrobin, and $\mathrm{AZOX}=$ azoxystrobin.

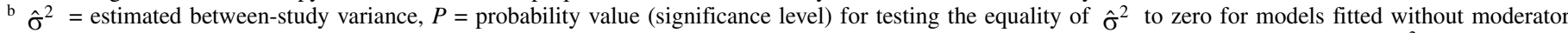
variable (Overall) and with baseline yield or foliar disease severity as a categorical moderator variable, LRS $=$ likelihood ratio statistic, and $R^{2}$ of Higgins and Thompson (20) (see text for explanation). For ease of presentation, $\hat{\sigma}^{2}$ was divided by 1,000.

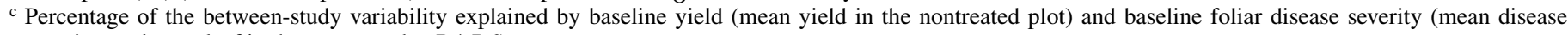
severity on the ear leaf in the nontreated at R4-R6). 
grain prices (Fig 4). For instance, when severity was $<5 \%$ and grain price was $\$ 0.16 / \mathrm{kg}$, $p_{\text {loss }}$ increased from 0.41 to 0.90 for pyraclostrobin; 0.54 to 0.84 for propiconazole + trifloxystrobin; 0.50 to 0.78 for propiconazole + azoxystrobin; and 0.83 to 0.99 for azoxystrobin as application cost increased from $\$ 40.00$ to $96.00 /$ ha. The corresponding increases when disease severity was $\geq 5 \%$ were from 0.24 to $0.78,0.19$ to $0.50,0.20$ to 0.47 , and 0.23 to 0.85 for pyraclostrobin, propiconazole + trifloxystrobin, propiconazole + azoxystrobin, and azoxystrobin, respectively. At an application cost of $\$ 65 / \mathrm{ha}, p_{\text {loss }}$ increased from 0.39 to 0.99 when disease severity was $<5 \%$ and from 0.18 to 0.98 when severity was $\geq 5 \%$ as grain price decreased from $\$ 0.28$ to $0.08 / \mathrm{kg}$.

For 205 of the $384(\approx 53 \%)$ grain price-application cost-fungicide scenarios that were considered, there was a $>70 \%$ chance of not seeing a return on investment when disease severity was $<5 \%$ $\left(p_{\text {loss }} \geq 0.70\right)$. For the low DIS_BASE category, there was $>75 \%$ chance of not obtaining a yield increase high enough to offset the cost of applying pyraclostrobin or azoxystrobin $\left(p_{\text {loss }} \geq 0.75\right)$ if grain price was $\$ 0.08 / \mathrm{kg}$ and fungicide application costs were $>\$ 40 /$ ha (Fig. 4). For the high DIS_BASE category and the two fungicides with the highest $\bar{D}$ values, propiconazole + trifloxystrobin and propiconazole + azoxystrobin, the chance of losing money on fungicide investment was $<25 \%$ ( $p_{\text {loss }}<0.25$ ) when grain prices were $>\$ 0.16 / \mathrm{kg}$ and application costs were $<\$ 65 / \mathrm{ha}$. The chance of at least recovering the cost of fungicide application through increased grain yield was greatest at the highest grain price and lowest fungicide application cost considered when disease severity was $\geq 5 \%$, being $88 \%$ for pyraclostrobin
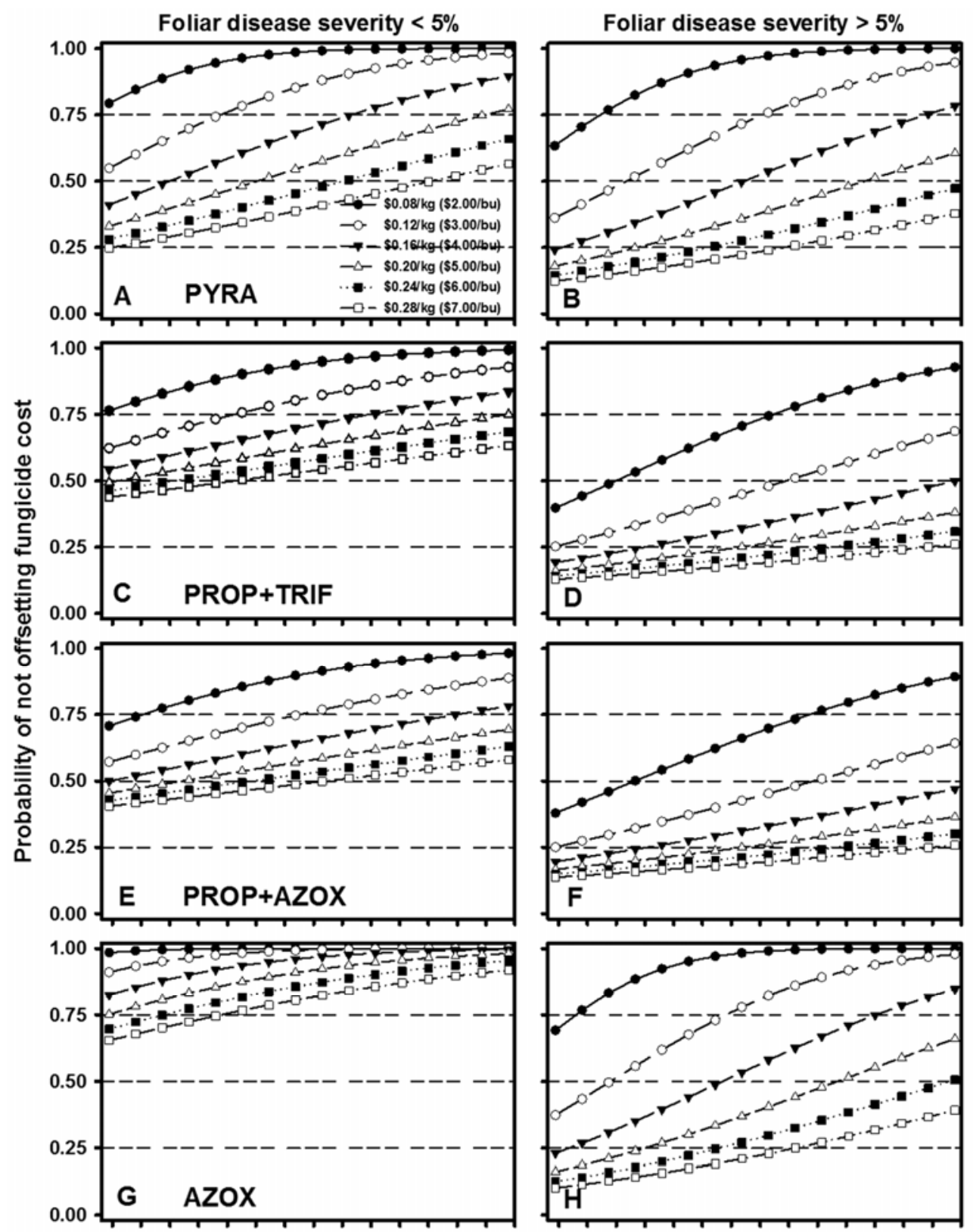

404448525660646872768084889296

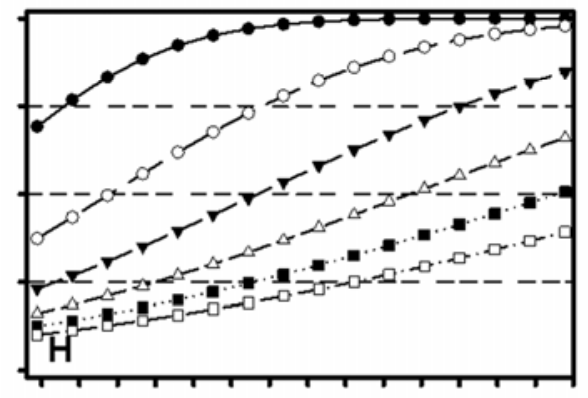

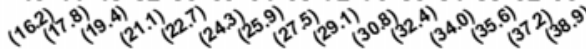

$4044485256 \quad 6064687276 \quad 8084889296$

\section{Fungicide application cost $[\$ / \mathrm{ha}(\$ / A c r e)]$}

Fig. 4. Probability of not offsetting fungicide application cost (product plus application) for a range of application costs and grain market prices for the fungicides $\mathbf{A}$ and B, pyraclostrobin, (PYRA); C and D, propiconazole + trifloxystrobin (PROP+TRIF); $\mathbf{E}$ and F, propiconazole + azoxystrobin (PROP+AZOX); and $\mathbf{G}$ and $\mathbf{H}$, azoxystrobin (AZOX), based on estimates of the mean yield difference $(\bar{D})$ and the between-study variance ( $\hat{\sigma}^{2}$ ) from meta-analyses of fungicide effects on grain yield, for studies with baseline foliar disease severity on the ear leaf in the nontreated plot $\mathbf{A}, \mathbf{C}, \mathbf{E}$, and $\mathbf{G},<5 \%$ and $\mathbf{B}, \mathbf{D}, \mathbf{F}$, and $\mathbf{H}, \geq 5 \%$. 
(i.e., $\left.1-p_{\text {loss }} \geq 0.88\right), 87 \%$ for propiconazole + trifloxystrobin, $86 \%$ for propiconazole + azoxystrobin, and $90 \%$ for azoxystrobin.

Similar results for $p_{\text {loss }}$ were found when YLD_BASE was used as the moderator variable (data not shown). In brief, $p_{\text {loss }}$ was the greater for the highest YLD_BASE categories than for the lowest YLD_BASE categories.

\section{DISCUSSION}

Since 2006, there has been a substantial increase in the application of foliar fungicides, especially those belonging to the QoI group of compounds, on hybrid field corn in the U.S. Corn Belt. This increase can at least be partially attributed to claims of "plant health", "plant performance", yield, and physiological benefits associated with fungicide applications (37). Many plant pathologists have questioned the magnitude of yield benefits associated with these physiological effects (37). To address these questions, several studies on corn have been conducted by both universityand industry-based researchers. Although the summaries of yield responses to fungicides presented by the different research groups show similar trends (with graphs similar to those shown in Figure 2), there have been different interpretations of the findings and, consequently, conclusions regarding the value and economics of using foliar fungicides in hybrid corn when foliar diseases are absent or at nominal levels (37).

Most of the previous conclusions regarding the effects of fungicides on hybrid corn yield were based on simple arithmetic means or a tally of studies with significant results (vote counting) $(27,37)$. Using data from fungicide trials conducted across the U.S. Corn Belt during 2002 to 2009, results presented here constitute the first comprehensive quantitative synthesis of hybrid corn yield response across a wide range of environments to four of the most widely used foliar fungicides. Through randomeffects meta-analyses, the overall mean yield difference (the effect size, $\bar{D}$ ) between treated and nontreated plots was determined for pyraclostrobin, propiconazole + trifloxystrobin, propiconazole + azoxystrobin, and azoxystrobin, all applied at label-recommended rates at either tasseling or silking. For all four products, there was a significant increase in yield relative to the nontreated plots. For three of the fungicides for which the yield increase was significant (pyraclostrobin, propiconazole + trifloxystrobin, and propiconazole + azoxystrobin), the magnitude of the response was affected by baseline foliar disease severity. $\bar{D}$ was generally greater for the higher disease severity category than the lower severity category. In addition, YLD_BASE affected the response to propiconazole + trifloxystrobin and propiconazole + azoxystrobin, with $\bar{D}$ being higher in the lowest YLD_BASE category than in the highest category.

The observed influence of YLD_BASE on the effect sizes and, consequently, the probability of profitable fungicide use is somewhat contrary to that reported in a similar investigation conducted by Munkvold et al. (38) based on a much smaller number of studies. These authors reported that the probability of profitable fungicide use in field corn was lower in fields with low yield potential and suggested that such fields should not be considered for fungicide application. There are several possible explanations for significantly higher effect sizes in the low YLD_BASE categories than in the higher categories. These include not only the inherent genetic yield potential of the hybrid but also environmental factors, yield-impacting stresses such as pest and diseases, hybrid resistance, and complex interactions involving these factors. It is quite possible for the profitability of fungicide use to be low in fields with high yield potential, especially if the hybrid is resistant or tolerant to foliar diseases. Munkvold et al. (38) also suggested that fungicide use was less likely to be profitable when resistant hybrids were planted, because resistant hybrids were observed to be less responsive to fungicide treatments than susceptible hybrids.
In general, YLD_BASE would be low when foliar disease severity is high $(66,68)$ and fungicide effects on foliar diseases could translate into a yield response $(58-62,66)$. The foliar disease effect was supported by results from our analysis of the effect of DIS_BASE on the mean yield response, which showed that $\bar{D}$ was higher in trials with disease severity $\geq 5 \%$ than in trials with severity $<5 \%$. As expected, results are less clear when foliar disease severity was not reported, although the trend for this category was for a smaller mean effect size compared with the situation with severity $\geq 5 \%$. Our findings are comparable with those from other studies, which showed that mean yield response to fungicides was higher for trials in which hybrids with fair to poor resistance to GLS were planted than in those planted with GLS-resistant hybrids $(37,38)$, and higher for trials in which corn was planted after corn than those in which corn was rotated with soybean (37). This is also consistent with the findings from studies on hybrid corn grain yield response to foliar diseases and defoliation $(1,26,66)$, the effects of genetic resistance on disease and yield responses $(12,27,38)$, and the value of using fungicides to minimize yield loss in corn when foliar disease levels are above critical thresholds $(1,38,54)$.

In addition to estimating the expected effect size and evaluating the influence of the moderator variables on the effect sizes, metaanalysis was used here to make projections regarding the probability of future outcomes and to assess the economic value of using a fungicide in hybrid corn when disease severity is $<5 \%$ and $\geq 5 \%$ (or yield was high or low). This is of particular importance because, from a farmer's perspective, it is not enough to know that a fungicide (or any other production practice, for that matter) may lead to a positive mean yield response in the long run. Knowing whether the average increase is large enough to offset the cost of applying the fungicide (and under what conditions this occurs) and the variability of the response are also important. At average grain prices and fungicide application costs over the study period, the mean yield increases of 64 to $306 \mathrm{~kg} / \mathrm{ha}$ in trials where disease severity was $<5 \%$, depending on the fungicide, generally were insufficient to offset the cost of fungicide application. The probability of not recovering the cost of applying a fungicide $\left(p_{\text {loss }}\right)$ at low disease severity was $>0.70$ for a wide range of application costs and grain prices, and $>0.5$ for almost every scenario considered. For all tested fungicides, $p_{\text {loss }}$ decreased with increasing grain price and decreasing application cost but, even at the highest grain price $(\$ 0.28 / \mathrm{kg}$ [ $\$ 7 / \mathrm{bushel}])$ and lowest fungicide application cost (\$40/ha $[\$ 16.20 /$ acre $])$, there was a 25,44 , 41 , and $65 \%$ chance of the yield increase being insufficient to cover the cost of applying pyraclostrobin, propiconazole + trifloxystrobin, propiconazole + azoxystrobin, and azoxystrobin, respectively, when disease severity was low.

Based on data from the United States Department of Agriculture, National Agricultural Statistics Service, grain corn prices have not reached $\$ 0.28 / \mathrm{kg}$ (\$7.00/bushel) in the last decade (1999 to 2009 ) but have been $\$ 0.06$ to $0.23 / \mathrm{kg}$ ( $\$ 1.53$ to $5.80 / \mathrm{bushel}$ ), with an average of $\$ 0.12 / \mathrm{kg}$ ( $\$ 2.97 / \mathrm{bushel})$. At this 10 -year average grain price and for application costs of $\$ 40$ to $95 / \mathrm{ha}$, the chance of failing to recoup expenses when disease severity was $<5 \%$ was 55 to $98 \%$ for pyraclostrobin, 62 to $93 \%$ for propiconazole + trifloxystrobin, 57 to $88 \%$ for propiconazole + azoxystrobin, and 91 to $99 \%$ for azoxystrobin. However, $p_{\text {loss }}$ was significantly lower when foliar disease severity was $\geq 5 \%$ on the ear leaf and, consequently, the probability of at least recovering the cost of fungicide application was higher in trials with $>5 \%$ severity, especially at low application costs and high grain prices. When baseline severity was $>5 \%, p_{\text {loss }}$ values at the 10 -year average grain price were $<0.50(0.28$ to 0.48$)$ for propiconazole + trifloxystrobin and propiconazole + azoxystrobin, at fungicide application costs of $<\$ 73 /$ ha. These results, based on meta-analysis, are comparable with those reported by Munkvold et al (38), based on Bayesian inference methods (5). They estimated profit probabili- 
ties of 0.02 to 0.98 (corresponding to $p_{\text {loss }}$ of 0.98 to 0.02 ) for a single application of propiconazole, based on grain prices of $\$ 0.79$ to $0.118 / \mathrm{kg}$ and an expected net return of $\$ 25 / \mathrm{ha}$. In that study, the highest profit probabilities (and, consequently, the lowest $p_{\text {loss }}$ values) occurred when susceptible hybrid were planted and GLS severity on the ear leaf was $>5 \%$ (22 to $73 \%$ ).

Accounting for YLD_BASE and DIS_BASE reduced $\hat{\sigma}^{2}$ but a substantial portion of the between-study variability remained unexplained. These large $\hat{\sigma}^{2}$ values suggest that other factors (unrecorded or not reported) contributed to the observed differences in yield response to fungicides among studies. This is not surprising, given that hybrid corn yield is a function of several crop-, environment-, pest-, and management-related factors $(13,16,50$, $51,57,65,66)$ and complex interactions involving these factors. Although YLD_BASE can be used as a surrogate risk factor for some of these effects, as was done here, the fact that this moderator variable only explained 2 to $11 \%$ of the between-study variability (for the fungicide for which its effect was statistically significant) suggests that a more direct investigation of the influence of factors such as soil type and fertility, temperature and moisture, weeds, pests, diseases, hybrid yield potential, pest and disease resistance, and cropping practices on yield response to fungicides will be needed to better determine the conditions under which the use of foliar fungicides may be more consistent and profitable. In addition, it is unclear what the 5\% disease severity cutoff means in terms of yield loss and fungicide decision thresholds. However, this information could be used as the basis for future studies to develop such thresholds and to refine corn foliar disease risk assessment models (45) to predict late-season disease intensity, based on information collected prior to making fungicide use decisions (before VT/R1).

At present, based on the results from this investigation, one cannot recommend these fungicides for general use when foliar disease risk is low. Foliar fungicides on field corn may be warranted and cost effective when disease severity would be $>5 \%$ in the absence of fungicide, grain prices are very high, application costs are low, and there is reasonable knowledge that yield would be low without treatment. However, there is great uncertainty, even when disease severity is $>5 \%$, that a grower would realize a profit in any given year and location when a fungicide is applied between VT and R1.

\section{ACKNOWLEDGMENTS}

Salaries and additional research support for P. A. Paul and L. V. Madden were provided by state and federal funds to the Ohio Agricultural Research and Development Center, The Ohio State University. Research in Mississippi was supported by the Mississippi Corn Promotion Board and special thanks are extended to N. Buehring, A. Henn, D. Ingram, and E. Larson for assisting with research in Mississippi. Salaries and additional research support for A. Grybauskas were provided by the Maryland Agricultural Experiment Station and the Maryland Grain Producers Utilization Board. Technical assistance in Maryland was provided by E. Reed, K. Conover, M. Sultenfuss, J. Street, and T. Ellis. Combine transport and maintenance in Maryland was provided by $\mathrm{R}$. Kratochvil, P. Forrestal, and P. Watkins. Partial support for the work done in Minnesota was provided by the University of Minnesota Agricultural Experiment Station. We thank E. Adee, K. Ames, and S. Ebelhar for assisting with the University of Illinois field trials; M. Wallhead, W. Bardall, J. Davlin, and M. Davis for assisting with Ohio trials; J. Shriver for assisting with trials in Iowa; and J. Beaty, G. Buechley, and T. McCarthy for assisting with trials in Indiana. This research was partially funded by BASF Corporation Agricultural Products, Research Triangle Park, NC; Bayer CropScience, Research Triangle Park, NC; and Syngenta Crop Protection Inc., Greensboro, NC.

\section{LITERATURE CITED}

1. Adee, E. A., Paul, L. E., Nafziger, E. D., and Bollero, G. 2005. Yield loss of corn hybrids to incremental defoliation. Online. Crop Management. doi: 10.1094/CM-2005-0427-01-RS.
2. Arends, L. R., Hoes, A. W., Lubsen, J., Grobbee, D. E., and Stijnen, T. 2000. Baseline risk as predictor of treatment benefit: three clinical metare-analyses. Stat. Med. 19:3497-3518.

3. Beckman, P. M., and Payne, G. A. 1982. External growth, penetration, and development of Cercospora zeae-maydis in corn leaves. Phytopathology 72:810-815.

4. Borenstein, M., Hedges, L. V., Higgins, J. P. T., and Rothstein, H. R. 2009. Introduction to Meta-Analysis. John Wiley \& Sons, Chichester, UK.

5. Box, G. E. P., and Tiao, G. C. 1973. Bayesian Inference in Statistical Analysis. Addison-Wesley, Reading, MA.

6. Bradley, C. A., and Ames, K. A. 2009. Evaluation of foliar fungicides on corn in Auburn, Illinois, 2008. Plant Disease Management Reports 3:FC001. Online publication. doi: 10.1094/PDMR03.

7. Bradley, C. A., and Ames, K. A. 2009. Evaluation of foliar fungicides on corn in Perry, Illinois, 2008. Plant Disease Management Reports 3:FC002. Online publication. doi: 10.1094/PDMR03.

8. Bradley, C. A., and Ames, K. A. 2009. Evaluation of foliar fungicides on corn in Urbana, Illinois, 2008. Plant Disease Management Reports 3:FC003. Online publication. doi: 10.1094/PDMR03.

9. Brand, R., and Kragt, H. 1992. Importance of trends in the interpretation of an overall odds ratio in the meta-analysis of clinical trials. Stat. Med. 11:2077-2082

10. de Nazareno, N. R. X., Lipps, P. E., and Madden, L. V. 1993. Effect of levels of corn residue on the epidemiology of gray leaf spot of corn in Ohio. Plant Dis. 77:67-70.

11. Field, A. P. 2001. Meta-analysis of correlation coefficients: A Monte Carlo comparison of fixed- and random-effects methods. Psychol. Methods 6:161-180.

12. Gorman, D., Anderson, B. M., and Abad, L. 1997. Yield loss of corn hybrids with differing levels of gray leaf spot resistance. Pages 171-182 in: Proc. Annu. Corn Sorghum Res. Conf., 52nd. American Seed Trade Association, Washington, DC

13. Gower, S. A., M. M. Loux, J. Cardina, and Harrison, S. K. 2002. Effect of planting date, residual herbicide, and postemergence application timing on weed control and grain yield in glyphosate-tolerant corn (Zea mays). Weed Technol. 16:488-494.

14. Grossman, K., Kwiatkowski, J., and Caspar, G., 1999. Regulation of phytohormone levels, leaf senescence and transpiration of the strobilurin kresoxim-methyl in wheat (Triticum aestivum). J. Plant Physiol. 154:805808.

15. Grossman, K., and Retzlaff, G. 1997. Bioregulatory effects of the fungicide strobilurin kresoxim-methyl in wheat (Triticum aestivum). Pestic. Sci. 50:11-20.

16. Grover, K. K., Roth, G. W., and Karsten, H. D. 2009. Corn grain yields and yield stability in four long-term cropping systems. Agron. J. 101:940946.

17. Hedges, L. V., Gurevitch, J., and Curtis, P. S. 1999. The meta-analysis of response ratios in experimental ecology. Ecology 80:1150-1156.

18. Hedges, L. V., and Olkin, I. 1980. Vote-counting methods in research synthesis. Psychol. Bull. 88:359-369.

19. Hedges, L. V., and Vevea, J. L. 1998. Fixed- and random-effects models in meta-analysis. Psychol. Methods 3:486-504.

20. Higgins, J. P. T., and Thompson, S. G. 2002. Quantifying heterogeneity in a meta-analysis. Stat. Med. 21:1539-1588.

21. Hunter, J. E., and Schmidt, F. L., 2004. Methods of Meta-Analysis: Correcting Error and Bias in Research Findings, 2nd ed. Sage Publications Inc., Thousand Oaks, CA.

22. Jackson, T. A. 2006. Evaluation of foliar fungicides on gray leaf spot of corn in Nebraska, 2005. Fungic. Nematicide Tests 61:FC041. Online publication. doi: 10.1094/FN61.

23. Jackson, T. A., Behn, J. L., and Miller, D. W. 2008. Evaluation of foliar fungicides on leaf diseases of corn in Nebraska, 2007. Plant Disease Management Reports 2:FC058. Online publication. doi: 10.1094/ PDMR02.

24. Jackson, T. A., Schleicher, C. M., and Behn, J. L. 2010. Evaluation of foliar fungicides on gray leaf spot of field corn in Nebraska, 2009. Plant Disease Management Reports 4:FC089. Online publication. doi: 10.1094/PDMR04.

25. Jackson, T. A., Schleicher, C. M., and Behn, J. L. 2010. Foliar fungicides efficacy on gray leaf spot of field corn in Nebraska, 2009. Plant Disease Management Reports 4:FC090. Online publication. doi: 10.1094/ PDMR04.

26. Jenco, J. H. 1995. Epidemiology of Cercospora zeae-maydis on Zea mays in Iowa. M.S. thesis, Iowa State University, Ames.

27. Jeschke, M., and Doerge, T. 2007. Management of foliar diseases in corn with fungicides. In: Crop Insights, 17, no. 14. Pioneer Hi-Bred, Johnston, IA.

28. Lee, C., P., and Vincelli, P. 2008. Evaluation of fungicides for control of gray leaf spot in corn, 2007. Plant Disease Management Reports 2:FC096. 
Online publication. doi: 10.1094/PDMR02.

29. Lee, C., P., and Vincelli, P. 2010. Evaluation of fungicide application on yield in field corn, 2008. Plant Disease Management Reports 4:FC019. Online publication. doi: 10.1094/PDMR04.

30. Lee, C., P., and Vincelli, P. 2010. Evaluation of fungicide application on disease intensity and yield in field corn, 2009. Plant Disease Management Reports 4:FC020. Online publication. doi: 10.1094/PDMR04.

31. Lipps, P. E. 1987. Gray leaf spot epiphytotic in Ohio corn. Plant Dis. $71: 281$.

32. Lipps, P. E. 1996. Reaction of corn hybrid to gray leaf spot. Pages 163 180 in: Proc. 51st Annu. Corn Sorghum Res. Conf. Chicago.

33. Lipps, P. E. 1998. Gray leaf spot: a global threat to corn production. APSnet Feature (May). Published online by The American Phytopathological Society, St. Paul, MN.

34. Lipsey, M. W., and Wilson, D. B. 2001. Practical Meta-Analysis. Sage Publications Inc., Thousand Oaks, CA.

35. Littell, R. C., Milliken, G. A., Stroup, W. W., Wolfinger, R. D., and Schabenberger, O. 2006. SAS for Mixed Models, 2nd ed. SAS Institute, Cary, NC.

36. Madden, L. V., and Paul, P. A. 2011. Meta-analysis for evidence synthesis in plant pathology: an overview. Phytopathology 101:16-30.

37. Munkvold, G. P., Doerge, T., and Bradley, C. 2008. IPM is still alive for corn leaf diseases: look before you spray. In: Proc. 62nd Annu. Corn Sorghum Res. Conf. Chicago. CD-ROM, American Seed Trade Association, Alexandria, VA..

38. Munkvold, G. P., Martinson, C. A., Shriver, J. M., and Dixon, P. M. 2001. Probabilities for profitable fungicide use against gray leaf spot in hybrid maize. Phytopathology 91:477-484.

39. Nason, M. A., Farrar, J., and Bartlett, D. 2007. Strobilurin fungicides induce changes to photosynthetic gas exchange that do not improve water use efficiency of plants grown under conditions of water stress. Pest Manage. Sci. 63:1191-1200.

40. Normand, S. L. T. 1999. Tutorial in biostatistics. Meta-analysis: formulating, evaluating, combining, and reporting. Stat. Med. 18:321-359.

41. Paul, P. A, Johnson, A. L., and Mills, D. R. P. 2008. Evaluation of fungicides for gray leaf spot control in field corn in Ohio, 2007. Plant Disease Management Reports 2:FC045. Online publication. doi: 10.1094/PDMR02

42. Paul, P. A., Lipps, P. E., Hershman, D. E., McMullen, M. P., Draper, M. A., and Madden, L. V. 2007. A quantitative review of tebuconazole effect on Fusarium head blight and deoxynivalenol content in wheat. Phytopathology 97:211-220.

43. Paul, P. A., Lipps, P. E., Hershman, D. E., McMullen, M. P., Draper, M. A., and Madden, L. V. 2008. Efficacy of triazole-based fungicides for Fusarium head blight and deoxynivalenol control in wheat: a multivariate meta-analysis. Phytopathology 98:999-1011.

44. Paul, P. A., Lipps, P. E., and Madden, L. V. 2005. Relationship between visual estimates of Fusarium head blight intensity and deoxynivalenol accumulation in harvested wheat grain: A meta-analysis. Phytopathology 95:1225-1236.

45. Paul, P. A., and Munkvold, G. P. 2004. A model-based approach to preplanting risk assessment for gray leaf spot of maize. Phytopathology 94:1350-1357.

46. Paul, P. A., and Munkvold, G. P. 2005. Influence of temperature and relative humidity on sporulation of Cercospora zeae-maydis and expansion of gray leaf spot lesions on maize leaves. Plant Dis. 89:624-630.

47. Paul, P. A, Wallhead, M. W., and Mills, D. R. P. 2009. Effects of fungicides on gray leaf spot and yield of field corn in Ohio, 2008. Plant Disease Management Reports 3:FC093. Online publication. doi: 10.1094/PDMR03.

48. Paul, P. A, Wallhead, M. W., and Mills, D. R. P. 2009. Gray leaf spot and yield responses to foliar fungicides in field corn in Ohio, 2008. Plant Disease Management Reports 3:FC092. Online publication. doi: 10.1094/PDMR03

49. Payne, G. A., Duncan, H. E., and Adkins, C. R. 1987. Influence of tillage on development of gray leaf spot and number of airborne conidia of Cercospora zeae maydis. Plant Dis. 71:329-332.

50. Raymond, F. D., Alley, M. M., Parrish, D. J., and Thomason, W. E. 2009.
Plant density and hybrid impacts on corn grain and forage yield and nutrient uptake. J. Plant Nutr. 32:395-409.

51. Riedell, W. E., Pikul, Jr., J. L., Jaradat, A, A., and Schumacher, T. E. 2009. Crop rotation and nitrogen input effects on soil fertility, maize mineral nutrition, yield, and seed composition. Agron. J. 101:870-879.

52. Ritchie, S. W., Hanway, J. J., and Benson, G. O. 1992. How a corn plant develops. Spec. Rep. No. 48. Iowa State Univ. Coop. Ext. Serv. Ames.

53. Rupe, J. C., Siegel, M. R., and Hartman, J. R. 1982. Influence of environment and plant maturity on gray leaf spot of corn caused by Cercospora zeae-maydis. Phytopathology 72:1587-1591.

54. Shah, D. A., and Dillard, H. R. 2010. Managing foliar diseases of processing sweet corn in New York with strobilurin fungicides. Plant Dis. 94:213-220.

55. Sheu, C. F., and Suzuki, S. 2001. Meta-analysis using linear mixed models. Behav. Res. Methods Ins. C. 33:102-107.

56. Shriver, J. M., and Robertson A. E. C. 2009. Comparison of fungicides for disease control and yield response of corn in Nashua, Iowa 2008. Plant Disease Management Reports 3:FC014. Online publication. doi: 10.1094/PDMR03.

57. Stanger, T. F., and Lauer, J. G. 2008. Corn grain yield response to crop rotation and nitrogen over 35 years. Agron. J. 100:643-650.

58. Stromberg, E. L., and Flinchum, L. E. 2003. Evaluation of foliar fungicides for the control of gray leaf spot of corn in Virginia, 2002. Fungic. Nematicide Tests 58:FC001. Online publication. doi: 10. 10.1094/FN58.

59. Stromberg, E. L., and Kenley, C. C. 2004. Evaluation of foliar fungicides for the control of gray leaf spot of corn in Virginia, 2003. Fungic. Nematicide Tests 59:CF021. Online publication. doi: 10.1094/FN58.

60. Stromberg, E. L., and Kenley, C. C. 2005. Evaluation of foliar fungicides for the control of gray leaf spot of corn in Virginia, 2004. Fungic. Nematicide Tests 60:FC074. Online publication. doi: 10.1094/FN60.

61. Stromberg, E. L., and Kenley, C. C. 2006. Evaluation of foliar fungicides for the control of gray leaf spot of corn in Virginia, 2005. Fungic. Nematicide Tests 61:FC061. Online publication. doi: 10.1094/FN61.

62. Stromberg, E. L., and Kenley, C. C. 2009. Evaluation of foliar fungicides for the control of gray leaf spot of corn in Virginia, 2008. Plant Disease Management Reports 3:FC017. Online publication. doi: 10.1094/ PDMR03.

63. Thorson, P. R., and Martinson, C. A. 1993. Development and survival of Cercospora zeae- maydis germlings in different relative humidity environments. Phytopathology 83:153-157.

64. van Houwelingen, H. C., Arends, L. R., and Stijnen, T. 2002. Advanced methods in meta-analysis: multivariate approach and meta-regression. Stat. Med. 21:589-624.

65. Viswakumar, A. Mullen, R. W., Sundermeier, A., and Dygert, C. E. 2008. Tillage and nitrogen application methodology impacts on corn grain yield. J. Plant Nutr. 31:1963-1974

66. Ward, J. M. J., Stromberg, E. L., Nowell, D. C., and Nutter, F. W., Jr. 1999. Gray leaf spot: a disease of global importance in maize production. Plant Dis. 83:884-895.

67. Wegulo, S. N., Martinson, C. A., Rivera-C., J. M., and Nutter, F. W., Jr. 1997. Model for economic analysis of fungicide usage in hybrid corn seed production. Plant Dis. 81:415-422.

68. Wegulo, S. N., Rivera-C, J. M., Martinson, C. A., and Nutter, F. W., Jr. 1998. Efficacy of fungicide treatments for control of common rust and northern leaf spot in hybrid corn seed production. Plant Dis. 82:547-554.

69. Wise, K., and Buechley, G. 2010. Efficacy of early applications of foliar fungicides on corn diseases and yield in Indiana, 2009. Plant Disease Management Reports 4:FC092. Online publication. doi: 10.1094/PDMR04.

70. Wise, K., and Buechley, G. 2010. Efficacy of foliar fungicides on corn diseases in central and southeastern Indiana, 2009. Plant Disease Management Reports 4:FC091. Online publication. doi: 10.1094/PDMR04.

71. Wise, K., and Buechley, G. 2010. Evaluation of foliar fungicides for management of corn diseases in Indiana, 2009. Plant Disease Management Reports 4:FC093. Online publication. doi: 10.1094/PDMR04.

72. Wu, Y.-X., and von Tiedemann, A. 2001. Physiological effects of azoxystrobin and epoxiconazole on senescence and the oxidative status of wheat. Pest. Biotechnol. Phys. 71:1-10. 